Original Article

\title{
The effects of bodyweight-based exercise with blood flow restriction on isokinetic knee muscular function and thigh circumference in college students
}

\author{
Dong Yeon Kang, PhD, $\mathrm{PT}^{1)}$, Hyoung Su Kim, PhD, $\mathrm{PT}^{1)^{*}}$, Kyung Soon Lee, PhD, $\mathrm{PT}^{1)}$, \\ Young Mi KIM, PhD, PT $^{2}$ \\ 1) Department of Physical Therapy, DongJu College: 55-gil, Sari-ro, Saha-gu, Busan 604-715, Repub- \\ lic of Korea \\ 2) Department of Physical Therapy, College of Rehabilitation Science, Daegu University, Republic of \\ Korea
}

\begin{abstract}
Purpose] The purpose of this study was to investigate the effects of bodyweight-based exercise with blood flow restriction on isokinetic muscular function and thigh circumference in college students. [Subjects and Methods] The subjects were 17 college students who were recruited and randomly assigned to bodyweight-based exercise with blood flow restriction and bodyweight-based exercise groups. Participants performed front lunges and squats at ratings of perceived exertion of 11-13 three times a week during a 6-week training period. The peak torque/ body weight (\%) of the knee flexor and extensor was measured using a HUMAC NORM System (Cybex $770-N_{O R M}{ }^{\circledR}$, Cybex International, Medway, MA, USA), and the circumference of the thigh was measured. PASW Statistics was used for data analysis. [Results] There were significant differences in the peak torque/ body weight (\%) of the flexors in both thighs (at $180 \% \mathrm{sec}$ ) after bodyweight-based exercise with blood flow restriction. In addition, the circumference changes in both thighs were significant after bodyweight-based exercise with blood flow restriction and between the two groups. [Conclusion] This study suggests that bodyweight-based exercise with blood flow restriction may be an effective method to improve the muscle power and hypertrophy of the lower extremity in a clinical setting.

Key words: Bodyweight-based exercise, Blood flow restriction, Isokinetic muscular function
\end{abstract}

(This article was submitted Apr. 15, 2015, and was accepted May 25, 2015)

\section{INTRODUCTION}

With resistance training, more than $70 \%$ of the one-repetition maximum (1RM) has traditionally been recommended as the optimal load for muscular strength and hypertrophy ${ }^{1)}$. However, this has recently been challenged by a number of studies $^{2-6)}$ demonstrating that substantial muscular strength and hypertrophy can be achieved with low-load (20-50\% of the 1RM) resistance exercise combined with blood flow restriction.

Previous researchers suggested that skeletal muscle could be subjected to high mechanical stress as a result of increased motor unit recruitment, cellular signaling events from mechanical changes in the muscle fibers or various endocrine responses ${ }^{7,8)}$. Therefore, blood flow restricted exercise may be a potentially useful method for promoting

\footnotetext{
*Corresponding author. Hyoung Su Kim (E-mail:
} Hyoungsu22@hanmail.net)

(c)2015 The Society of Physical Therapy Science. Published by IPEC Inc. This is an open-access article distributed under the terms of the Creative Commons Attribution Non-Commercial No Derivatives (by-ncnd) License $<$ http://creativecommons.org/licenses/by-nc-nd/3.0/> . muscle hypertrophy in people with various problems, avoiding exercises with heavy loads ${ }^{9)}$. However, although this has been confirmed as safe and effective exercise by studies ${ }^{9-11)}$ on skeletal muscle, measurement of the 1RM is not easy in frail or elderly patients. Specifically, the American College of Sports Medicine (ACSM) ${ }^{12}$ ) has recommended relative contraindications not only for resistance training but also for testing of the 1RM for cardiovascular disease patients with low functional capacity ( $<4$ METs) or musculoskeletal limitations. Therefore, in the case of rehabilitation for patients after cast immobilization, for example, rehabilitation programs should be designed to increase muscular strength and hypertrophy using bodyweight-based exercise in a physical therapy setting, and this would be a safe and effective intervention for increasing muscular strength and hypertrophy. To date, there is no information regarding this. Therefore, it is important to determine whether there are beneficial effects of bodyweight-based exercise using blood flow restriction in physiotherapy. It was previously reported that blood flow in a muscle could be decreased in blood flow restriction training by application of a wrap.

Most of these studies ${ }^{2-6)}$ were performed using the Kaatsu Master system (Sato Sports Plaza, Tokyo, Japan). However, the Kaatsu Master system may not be a practical approach 
Table 1. Comparisons of muscular strength and power of the lower extremities

\begin{tabular}{|c|c|c|c|c|c|c|c|}
\hline & & \multicolumn{6}{|c|}{$60 \% \mathrm{sec}$} \\
\hline & & \multicolumn{3}{|c|}{ Knee extensor peak torque / body weight (Nm) } & \multicolumn{3}{|c|}{ Knee flexor peak torque / body weight (Nm) } \\
\hline & & Pre & Post & Difference $(\%)$ & Pre & Post & Difference $(\%)$ \\
\hline \multirow{2}{*}{ Right } & BFR & $181.7 \pm 66.3$ & $190.8 \pm 44.3$ & $9.4 \pm 19.3$ & $107.2 \pm 37.6$ & $126.5 \pm 38.1 * *$ & $20.2 \pm 15.2$ \\
\hline & WBE & $165.5 \pm 57.3$ & $154.0 \pm 45.8$ & $-5.1 \pm 8.0$ & $91.8 \pm 30.2$ & $98.7 \pm 26.5$ & $11.0 \pm 18.7$ \\
\hline \multirow{5}{*}{ Left } & BFR & $177.3 \pm 49.3$ & $169.8 \pm 39.8$ & $-2.8 \pm 11.1$ & $108.8 \pm 29.7$ & $116.3 \pm 35.5$ & $6.5 \pm 12.1$ \\
\hline & WBE & $174.5 \pm 50.3$ & $151.1 \pm 37.1$ & $-11.7 \pm 12.0$ & $98.1 \pm 30.5$ & $90.8 \pm 27.6$ & $-7.4 \pm 16.2$ \\
\hline & & \multicolumn{6}{|c|}{$180^{\circ} / \mathrm{sec}$} \\
\hline & & \multicolumn{3}{|c|}{ Knee extensor peak torque / body weight (Nm) } & \multicolumn{3}{|c|}{ Knee flexor peak torque / body weight (Nm) } \\
\hline & & Pre & Post & Difference $(\%)$ & Pre & Post & Difference $(\%)$ \\
\hline \multirow{2}{*}{ Right } & BFR & $107.5 \pm 40.4$ & $117.8 \pm 30.4$ & $14.3 \pm 20.1$ & $78.8 \pm 24.8$ & $92.3 \pm 24.8^{*}$ & $14.1 \pm 15.3$ \\
\hline & WBE & $108.4 \pm 25.6$ & $111.8 \pm 25.1$ & $3.8 \pm 11.6$ & $68.5 \pm 15.4$ & $79.4 \pm 18.6^{* * *}$ & $13.3 \pm 4.1$ \\
\hline \multirow{2}{*}{ Left } & BFR & $111.2 \pm 32.3$ & $111.0 \pm 20.4$ & $-0.0 \pm 19.6$ & $79.3 \pm 20.2$ & $86.0 \pm 18.05^{*}$ & $10.2 \pm 14.09$ \\
\hline & WBE & $114.4 \pm 30.3$ & $111.0 \pm 24.4$ & $12.6 \pm 10.6$ & $74.5 \pm 19.0$ & $76.5 \pm 19.8$ & $3.0 \pm 14.5$ \\
\hline
\end{tabular}

Mean \pm SD

BFR: bodyweight-based exercise with blood flow restriction, WBE: bodyweight-based exercise $* \mathrm{p}<0.05, * * \mathrm{p}<0.01, * * \mathrm{p}<0.001$

for most populations due to cost and accessibility ${ }^{13)}$.

Therefore, the purpose of this study was to investigate the effects of bodyweight-based exercise with blood flow restriction using a wrap on isokinetic muscular function and thigh circumference in college students. In addition, it will provide the basic data necessary for therapeutic interventions, such as surgery, neurophysiological treatment, and specific treatments for elderly people.

\section{SUBJECTS AND METHODS}

The subjects of this study were 17 college students. They were divided into two groups: a bodyweight-based exercise with blood flow restriction (BFR) group and a bodyweightbased exercise (WBE) group. There were 10 subjects in the BFR group ( 3 male, 7 female) and 7 subjects in the WBE group (2 male, 5 female). Their general characteristics were as follows: age, height, weight, percent body fat, and lean body mass were $24.0 \pm 3.2$ years and $26.8 \pm 4.6$ years, $166.2 \pm 7.2 \mathrm{~cm}$ and $166.5 \pm 8.0 \mathrm{~cm}, \quad 58.3 \pm 12.1 \mathrm{~kg}$ and $67.6 \pm 11.7 \mathrm{~kg}, 21.7 \pm 6.4 \%$ and $26.8 \pm 8.1 \%$, and $45.4 \pm 8.6 \mathrm{~kg}$ and $49.1 \pm 7.9 \mathrm{~kg}$ for BFR and WBE groups, respectively. All participants understood the purpose of this study and provided written informed consent prior to participation in accordance with the ethical principles of the Declaration of Helsinki.

An isokinetic knee muscular function test was performed using a HUMAC NORM System (Cybex 770-NORM ${ }^{\circledR}$, Cybex International, Medway, MA, USA), and it measured muscular strength and power. The test protocol was based on those of the previous studies ${ }^{14,15)}$. The extensor and flexor of the both knee joints were evaluated 10 times each at $60 \%$ sec (muscular strength) and 15 times each at $180 \% \mathrm{sec}$ (muscular power), and the peak torque/body weight (\%) was calculated from the results. Thigh circumference was measured directly below the gluteal fold of both thighs ${ }^{16)}$. All measurements were taken 24 hours before the first round of exercise and 24 hours after the last round of exercise. As for the wrap, studies that used an elastic wrap ${ }^{13)}$ or the Kaatsu Master system (Sato Sports Plaza, Tokyo, Japan) ${ }^{2-6}$ ) were referred to. The wrap's width was set at $5 \mathrm{~cm}$, and its length was set at $100-130 \mathrm{~cm}$, about two times the thigh girth; when applied, it resulted in a rating of perceived exertion (RPE, Borg's 6-20 scale) of 11-13 at the end of each motion.

Front lunges and squats were performed using the wrap around the proximal aspect of the thigh in the BFR group, and conventional exercise without blood flow restriction was performed in the WBE group. The exercise protocol was performed with an RPE of 11-13 for 30 minutes once a day and 3 times a week for 6 weeks. Regarding exercise intensity, the initial intensity was set as the number of times in which the RPE was 11-13 at the end of 10-15 repetitions of each motion, and the intensity was reset every 2 weeks.

The data were statistically processed, paired sample ttests were conducted for within-group comparisons, and the changes before and after the training program were calculated. Comparisons between the two groups were conducted by independent sample t-tests. Statistical significance was set at $\mathrm{p}<0.05$, and PASW Statistics 18.0 version was used for the analysis.

\section{RESULTS}

Isokinetic knee muscular function was compared between the BFR and WBE groups (Table 1). The BFR group showed a significant improvement in $60 \% \mathrm{sec}$ peak torque/ body weight $(\%)$ at the flexor of the right knee $(\mathrm{p}<0.01)$ and $180 \%$ sec peak torque/body weight $(\%)$ at the flexor of both knees after exercise $(\mathrm{p}<0.05)$. In addition, the WBE group's $180^{\circ} / \mathrm{sec}$ peak torque/body weight $(\%)$ at the flexor of the knee after exercise increased significantly $(\mathrm{p}<0.001)$. There was no significant difference between the two groups in isokinetic knee muscular function $(\mathrm{p}<0.05)$.

Thigh circumference was compared between the BFR and WBE groups (Table 2). The BFR group saw a significant increase in the right and left legs after the exercise compared 
Table 2. Comparisons of thigh circumference

\begin{tabular}{|c|c|c|c|c|c|c|}
\hline & \multicolumn{3}{|c|}{ Right (cm) } & \multicolumn{3}{|c|}{ Left $(\mathrm{cm})$} \\
\hline & Pre & Post & Difference (\%) & Pre & Post & Difference (\%) \\
\hline BFR & $45.5 \pm 3.8$ & $47.9 \pm 4.5^{* * *}$ & $5.3 \pm 2.8 * * *$ & $45.4 \pm 4.1$ & $47.8 \pm 4.5^{* * *}$ & $5.1 \pm 2.6^{* *}$ \\
\hline WBE & $49.7 \pm 5.5$ & $49.4 \pm 5.0$ & $-0.4 \pm 2.1$ & $50.1 \pm 6.8$ & $50.4 \pm 6.3$ & $0.7 \pm 2.1$ \\
\hline
\end{tabular}

with before $(p<0.001)$. In comparison between the BFR and WBE groups, the circumferences of both thighs in the BFR group increased significantly $(p<0.001, p<0.01)$ after the exercise compared with before the exercise.

\section{DISCUSSION}

Although BFR exercise has been confirmed as safe and effective exercise by studies ${ }^{9-11)}$ on skeletal muscle, it was reported that reperfusion after a BFR leads to impairment of local endothelial function ${ }^{17}$ ), and the mechanisms of restricted blood flow exercise were not clarified. However, it is certain that, BFR exercise can bring about improvements in muscle strength and muscular hypertrophy. Previous researchers have thought that muscular hypertrophy was attributed to decreased oxygen available to the muscle and accumulation of metabolites such as lactic acid during BFR training. In addition, early recruitment of fast twitch (type II) fiber might occur to maintain the muscular force and protect against conduction failure during restricted blood flow exercise because of reduced oxygen supply to slow twitch (type I) fiber ${ }^{2,3,18)}$

The main objective of this study was to compare with the effects of BFR using wraps on the isokinetic muscular function of the lower extremity and thigh circumference in college students. Our major findings showed that BFR using wraps could elicit improvements in the muscular power of the knee flexor and hypertrophy in college students. In particular, significant differences in the circumferences of the thighs were found between the two groups. This was in agreement with an earlier study. In that study, soccer players $(\mathrm{n}=16)$ performed 3 sets of blood flow restriction training (bench press, squat) with a wrapping consisting of an elastic band, 3 times a week for 4 weeks at $20 \%$ of $1 \mathrm{RM}$, and the $1 \mathrm{RM}$ values of the upper and lower extremities (bench press and squat) increased significantly, that is, by $7.0 \%$ and $8.0 \%$, respectively $(\mathrm{p}<0.05)^{19)}$.

This result was similar to that of a study ${ }^{20)}$ of 21 subjects (22.1 \pm 1.8 years) who were divided into four groups, without any pressure $(\mathrm{n}=5)$, with a pressure of $50 \mathrm{mmHg}(\mathrm{n}=5)$, with a pressure of $150 \mathrm{mmHg}(\mathrm{n}=5)$, and with a pressure of $250 \mathrm{mmHg}(\mathrm{n}=6)$, and performed straight leg raises, hip adduction, and hip abduction 3 times a week for 8 weeks at $20 \%$ of $1 \mathrm{RM}$. A significant improvement in $180 \%$ s peak torque/body weight $(\%)$ (muscle power) was observed (p < $0.05, \mathrm{p}<0.01)$ after training in the low-pressure group (50 $\mathrm{mmHg}$ ).

We believe these results were induced by the wraps restricting blood flow in the exercised muscle. In the current study, bodyweight-based exercise with a wrap was performed without an air compressor. However, it brought about improvements in muscular power. We believe the improved muscular power was due mainly to neural adaptations of the lower extremities. The reason for this is as follows. It has been reported that the neural factors were the greatest contributors to increasing muscular strength during the initial 8 to 10 weeks of resistance training. In particular, fast twitch fiber is associated with speed or power activities ${ }^{21)}$.

It was particularly noteworthy that BFR using wraps for 6 weeks resulted in a clear increase in muscular power and hypertrophy in the lower extremities in this study. The results of this study were similar to those of blood flow restriction exercise with knee wraps, which showed the same degree of muscle hypertrophy in high-intensity resistance training in a previous study ${ }^{13)}$.

We consider that the increase in the circumference of the thigh after intervention is due to the combination of training effects on the hamstring muscle not used ordinarily and the BFR effect through the front lunge and squat exercises in the college students because front lunge and squat exercises are primarily performed in a bodyweight-based position ${ }^{22)}$ and the knee flexors, the hamstring muscles, are mainly used when the front lunge and squat motions are performed. Moreover, previous investigators reported that squatting helps to strengthen the quadriceps and stimulates coactivation of the hamstrings ${ }^{23)}$.

In conclusion, this study suggested bodyweight-based exercise with blood flow restriction is a useful method to improve the flexor functions of the legs in a clinical setting.

\section{REFERENCES}

1) Manini TM, Clark BC: Blood flow restricted exercise and skeletal muscle health. Exerc Sport Sci Rev, 2009, 37: 78-85. [Medline] [CrossRef]

2) Loenneke JP, Wilson JM, Marín PJ, et al.: Low intensity blood flow restriction training: a meta-analysis. Eur J Appl Physiol, 2012, 112: 1849-1859. [Medline] [CrossRef]

3) Scott BR, Loenneke JP, Slattery KM, et al.: Exercise with blood flow restriction: an updated evidence-based approach for enhanced muscular development. Sports Med, 2015, 45: 313-325. [Medline] [CrossRef]

4) Suga $\mathrm{T}$, Okita $\mathrm{K}$, Morita N, et al.: Intramuscular metabolism during lowintensity resistance exercise with blood flow restriction. J Appl Physiol 1985, 2009, 106: 1119-1124. [Medline] [CrossRef]

5) Fry CS, Glynn EL, Drummond MJ, et al.: Blood flow restriction exercise stimulates mTORC1 signaling and muscle protein synthesis in older men. J Appl Physiol 1985, 2010, 108: 1199-1209. [Medline] [CrossRef]

6) Loenneke JP, Fahs CA, Rossow LM, et al.: Effects of cuff width on arterial occlusion: implications for blood flow restricted exercise. Eur J Appl Physiol, 2012, 112: 2903-2912. [Medline] [CrossRef]

7) Cook SB, Brown KA, Deruisseau K, et al.: Skeletal muscle adaptation following blood flow-restricted training during 30 days of muscular unloading. J Appl Physiol 1985, 2010, 109: 341-349. [Medline] [CrossRef] 
8) Kim E, Gregg LD, Kim L, et al.: Hormone responses to an acute bout of low intensity blood flow restricted resistance exercise in college-aged females. J Sports Sci Med, 2014, 13: 91-96. [Medline]

9) Abe T, Loenneke JP, Fahs CA, et al.: Exercise intensity and muscle hypertrophy in blood flow-restricted limbs and non-restricted muscles: a brief review. Clin Physiol Funct Imaging, 2012, 32: 247-252. [Medline] [CrossRef]

10) Vieira PJ, Chiappa GR, Umpierre D, et al.: Hemodynamic responses to resistance exercise with restricted blood flow in young and older men. J Strength Cond Res, 2013, 27: 2288-2294. [Medline] [CrossRef]

11) Loenneke JP, Wilson JM, Wilson GJ, et al.: Potential safety issues with blood flow restriction training. Scand J Med Sci Sports, 2011, 21: 510-518. [Medline] [CrossRef]

12) Medicine ACos: ACSM's Guidelines for Exercise Testing and Prescription. 2014.

13) Lowery RP, Joy JM, Loenneke JP, et al.: Practical blood flow restriction training increases muscle hypertrophy during a periodized resistance training programme. Clin Physiol Funct Imaging, 2014, 34: 317-321. [Medline] [CrossRef]

14) Impellizzeri FM, Bizzini M, Rampinini $\mathrm{E}$, et al.: Reliability of isokinetic strength imbalance ratios measured using the Cybex NORM dynamometer. Clin Physiol Funct Imaging, 2008, 28: 113-119. [Medline] [CrossRef]

15) Uchiyama $\mathrm{K}$, Miaki $\mathrm{H}$, Terada $\mathrm{S}$, et al.: Effect of muscle strength training and muscle endurance training on muscle deoxygenation level and endur- ance performance. J Phys Ther Sci, 2011, 23: 349-355. [CrossRef]

16) Jung KJ, Kimm H, Yun JE, et al.: Thigh circumference and diabetes: obesity as a potential effect modifier. J Epidemiol, 2013, 23: 329-336. [Medline] [CrossRef]

17) Renzi CP, Tanaka H, Sugawara J: Effects of leg blood flow restriction during walking on cardiovascular function. Med Sci Sports Exerc, 2010, 42: 726-732. [Medline] [CrossRef]

18) Kim LJ: Changes of compound muscle action potential after low-intensity exercise with transient restriction of blood flow: a randomized, placebocontrolled trial. J Phys Ther Sci, 2009, 21: 361-366. [CrossRef]

19) Yamanaka T, Farley RS, Caputo JL: Occlusion training increases muscular strength in division IA football players. J Strength Cond Res, 2012, 26: 2523-2529. [Medline] [CrossRef]

20) Sumide T, Sakuraba K, Sawaki K, et al.: Effect of resistance exercise training combined with relatively low vascular occlusion. J Sci Med Sport, 2009, 12: 107-112. [Medline] [CrossRef]

21) GH W: Physiology of Sports and Exercise, 4th ed. Champaign: Human Kinetics, 2008

22) Kisner CC: Therapeutic Exercise, 5th ed. Philadelphia: F.A. Davis, 2007.

23) Jan $\mathrm{MH}$, Lin $\mathrm{CH}$, Lin $\mathrm{YF}$, et al.: Effects of weight-bearing versus nonweight-bearing exercise on function, walking speed, and position sense in participants with knee osteoarthritis: a randomized controlled trial. Arch Phys Med Rehabil, 2009, 90: 897-904. [Medline] [CrossRef] 